\title{
Optimization algorithm and simulation of supply chain coordination based on cross-border E-commerce network platform
}

Deli Wang and Wuwei Li

*Correspondence: wwlidh@126.com Glorious Sun School of Business and Management, Donghua University, Shanghai 200051, China

\begin{abstract}
With the rapid development of cross-border e-commerce, the improvement of consumer satisfaction has become the focus of cross-border e-commerce platform optimization. Relying on advanced algorithm technology, it can realize the accurate and efficient matching between massive information and users, which is conducive to improving the user experience. Based on the consideration of consumer satisfaction, this paper constructs a dual channel supply chain composed of cross-border suppliers, cross-border e-commerce enterprises, retailers and consumers and studies the revenue and cost sharing contract of the supply chain under the conditions of centralized decision and decentralized decision. The research shows that cross-border e-commerce enterprises can choose to form revenue and expenditure sharing contracts through online and offline channels, optimize decentralized decision-making, and achieve winwin cooperation among supply chain entities.
\end{abstract}

Keywords: Cross border e-commerce, Consumer satisfaction, Stackelberg game, Supply chain coordination

\section{Introduction}

With the support of national policies and the promotion of Internet technology, crossborder e-commerce industry has contributed an important force to China's economic growth. China's cross-border e-commerce enterprises are growing rapidly and the market scale is expanding continuously. In 2019, more than 6000 cross-border e-commerce enterprises have been added, with 300 million packages being sent to the world, and the total import and export volume of cross-border e-commerce has reached 186.21 billion yuan. Cross-border e-commerce has gradually become an important part of foreign trade. However, the development of cross-border e-commerce is still faced with the problems of slow logistics, high price and difficulty for users to directly contact products, which has affected consumer satisfaction. Therefore, we can improve consumer satisfaction, improve enterprise profits and achieve win-win cooperation through online and offline channels.

From the perspective of cross-border e-commerce, in the context of the development of Internet technology and economic globalization, cross-border e-commerce has

(c) The Author(s) 2021. This article is licensed under a Creative Commons Attribution 4.0 International License, which permits use, sharing, adaptation, distribution and reproduction in any medium or format, as long as you give appropriate credit to the original author(s) and the source, provide a link to the Creative Commons licence, and indicate if changes were made. The images or other third party material in this article are included in the article's Creative Commons licence, unless indicated otherwise in a credit line to the material. If material is not included in the article's Creative Commons licence and your intended use is not permitted by statutory regulation or exceeds the permitted use, you will need to obtain permission directly from the copyright holder. To view a copy of this licence, visit http://creativecommons. org/licenses/by/4.0/. 
gradually penetrated into all aspects of social life. Under the background of big data, considering the personalized needs of customers, Li Jiahua studied the intelligent recommendation algorithm of cross-border e-commerce shopping guide platform through big data technology [1]. In order to solve the problem of privacy leakage in gene research, Wu Xiang et al. proposed a motif search algorithm, which can protect privacy and obtain high-quality model results [2]. Liang Haibo et al. used the improved genetic algorithm to optimize the traditional controller and proved the superiority of the method by comparing the model of the traditional controller with the optimized controller [3]. Under the background of the development of artificial intelligence, Chen Zhijun and others know the driver's driving state through unsupervised road test [4]. Zheng Haifeng and others proposed a data relay scheme to improve the performance of wireless sensor networks [5]. Liu Dingrui et al. take overseas manufacturers and cross-border manufacturers as research objects and take the service level and product perceived value of offline and online channels as key indicators to analyze the optimal decision-making and profit change of each member of the dual channel supply chain [6]. Based on the establishment of trade gravity model, Zhao Y N analyzes the factors influencing the cooperation between other countries and China [7]. Wu Xiang et al. use natural language processing (NLP) technology and grey relational analysis (GRA) to improve the performance and resource utilization of applications [8]. Considering the competition and cooperation between upstream and downstream enterprises, Liu Zheng et al. studied how to use the responsibility sharing and resource sharing among enterprises to manage the carbon emission of supply chain [9]. Liang Haibo et al. applied artificial intelligence to oil drilling leakage cases and proposed an algorithm based on PSO-SVR to dynamically evaluate the risk in the drilling process [10].

From the perspective of algorithm optimization, relying on cloud computing, big data, artificial intelligence and other advanced technologies, it can realize the accurate and efficient matching between massive information and cross-border e-commerce users, which is conducive to improving the user experience. According to the trajectory of human behavior, we can observe people's movement. In order to ensure public safety, Chen Zhijun and others proposed a method that can automatically identify the trajectory of pedestrian behavior to reduce the workload of monitoring work [11]. Based on association rules, Yang Hongyan et al. track the consumer satisfaction data of a province and analyze the change trend of consumer satisfaction and the factors that affect these changes [12]. Liu Zheng and others used the bus simulation data to design the bus pricing model to improve the company's profit and customer satisfaction [13]. Ma Fengcai et al. used the review information of Jingdong e-commerce platform, selected logistics speed, product packaging, service quality and product price as key indicators to study the overall situation of customer satisfaction with fresh products [14]. Xiong $\mathrm{N}$ et al. analyzed and summarized the network-based GCC scheme by combing the background of green cloud computing [15]. SEO et al. conducted a questionnaire survey on consumers to study the influence of the image of imported products and wordof-mouth on consumer satisfaction and purchase intention and evaluated the influence of familiarity on consumer satisfaction and purchase intention [16]. Based on the probability model, Zhang Mingyang et al. evaluated the human error in ship navigation and reduced the probability of risk occurrence [17]. Guo Wenzhong et al. have developed an 
algorithm that can schedule tasks in wireless sensor networks, and its effectiveness has been proved by simulation [18].

From the perspective of supply chain coordination, with the changes of consumers' requirements for product quality and time, how to design a scientific coordination mechanism for the supply chain is a problem that enterprises need to solve [19]. Taking the channel disputes caused by customers' delivery time requirements into account, $\mathrm{Xu}$ Fei et al. established an optimization model for the cooperation between manufacturers and retailers with different delivery dates and designed a scheme for online and offline channel optimization and coordination [20]. Shu et al. constructed a supply chain composed of manufacturers and online retailers and considered the logistics service and product price under the condition of whether they cooperated or not, and realized the supply chain coordination through contract [21]. Taking the two-level supply chain composed of suppliers and retailers as the research object, Li Yanbing et al. analyzed the optimal decision-making under the conditions of centralized decision-making, decentralized decision-making and repurchase contract and conceived a coordination optimization method of repurchase contract considering cost profit rate [22]. Ma Xueli et al. constructed a three-level supply chain composed of farmers, logistics suppliers and retailers. Taking agricultural products as the research object, they conceived coordination contracts to realize the income balance of supply chain members [23]. Liu Zheng et al. studied the optimization of supply chain through the comparison of optimal decisions and met the requirements of carbon emission and profit of enterprises [24]. Based on the uncertainty of retailers' demand and risk attitude, HêrişGolpîra et al. designed a profit-oriented contract and considered the coordination problem of power supply chain by using newsboy model [25].

After literature review on cross-border e-commerce, consumer satisfaction and supply chain coordination, we can see that cross-border e-commerce is closely related to consumer satisfaction, and consumer satisfaction is an important factor to evaluate cross-border e-commerce enterprises [26-28]. However, few literature can consider improving consumer satisfaction from the perspective of cross-border e-commerce supply chain coordination [29-32]. Through the coordination of online and offline channels of cross-border e-commerce enterprises, it not only brings better consumer experience, improves consumer satisfaction, but also improves the profits of the main body of the supply chain [33-35]. From the perspective of consumer satisfaction, this paper considers the coordination and optimization between online and offline channels in the supply chain of cross-border e-commerce enterprises [36-39].

The remainder of this paper is organized as follows: the hypothesis and basic decision-making model under the constraint of the carbon tax are introduced in Sect. 2 and Sect. 3. Experimental results are presented in Sect. 4 and Conclusions are drawn in the last section.

\section{Related work}

\subsection{Model hypothesis}

Taking the supply chain of cross-border e-commerce enterprises as the research object, this paper constructs a dual channel supply chain composed of cross-border suppliers, cross-border e-commerce enterprises, overseas retailers and overseas consumers, as 
shown in Fig. 1. Based on consumers' satisfaction with products, this paper analyzes and compares the optimal decision-making of supply chain in three situations: decentralized decision-making centralized decision-making and revenue and cost sharing contract, with online channel as the leading factor. This paper aims to study the following problems:

1. The game models of centralized decision-making, decentralized decision-making and revenue and cost sharing contract are established, and the optimal decisionmaking under different modes is compared, and the optimal way is selected to coordinate the cross-border e-commerce supply chain [40-42].

2. We should improve consumers' satisfaction with products, improve their online and offline consumption experience, establish brand image, improve product competitiveness and attract consumers to become loyal users of cross-border products [4346].

3. One of the purposes of supply chain coordination of cross-border e-commerce enterprises is to improve the overall profit of the supply chain. By comparing the profits of the supply chain system under different modes, the most suitable mode of supply chain optimization is selected [47-50].

\subsection{Parameters description}

In Table 1, we can see affected by the estimated utility of products, product price and logistics speed, it can be assumed that the consumer satisfaction function of online channels is $S_{1}=\alpha \lambda-P 1-\eta T$. When overseas consumers purchase products through offline channels, they can directly contact the products. At this time, $\lambda=1$, and not limited by the delivery time, but by the travel factors of consumers, resulting in travel and time costs, the consumer satisfaction function of offline channels is $S_{2}=\alpha-P 2-\beta$. If the consumer's offline product satisfaction is greater than the online product satisfaction, there is $S_{1}<S_{2}$, consumers choose offline channel to purchase products. If the consumer's offline product satisfaction is less than the online product satisfaction, there is $S_{1}>S_{2}$, consumers choose online channel to purchase products. $\alpha_{1}$ is used to represent the estimated utility value (critical value) when the online channel customer satisfaction is zero, $\alpha_{1}=\frac{P 1+\eta T}{\lambda}$, $\alpha_{2}$ is the estimated utility value (critical value) when the offline channel consumer satisfaction is $0, \alpha_{2}=P 2+\beta$, and $\alpha_{3}$ is the estimated utility value when the online and offline

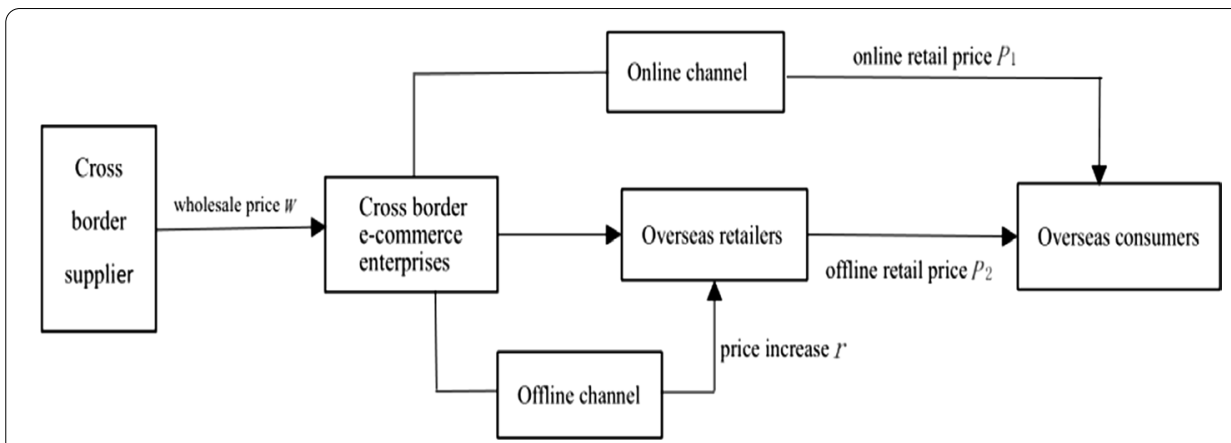

Fig. 1 Cross-border e-commerce dual-channel supply chain 
Table 1 Description of each parameter

\begin{tabular}{|c|c|}
\hline parameters & Description of each parameter \\
\hline$w$ & $\begin{array}{l}\text { Wholesale price of products sold by cross-border suppliers to cross-border e-commerce enter- } \\
\text { prises }\end{array}$ \\
\hline$r$ & Cross-border suppliers mark up their products and sell them to retailers \\
\hline P1 & Price of cross-border e-commerce online channel products (domestic delivery) \\
\hline$P 2$ & Cross-border e-commerce offline channel product price (offline physical store) \\
\hline$T$ & Stipulated delivery time of products sold by cross-border e-commerce through online channels \\
\hline$t$ & Actual arrival time of cross-border e-commerce products sold through online channels \\
\hline$\alpha$ & $\begin{array}{l}\text { The estimated utility of a product by a consumer means that the consumer has estimated the } \\
\text { quality, material and other characteristics of the product before receiving the product }\end{array}$ \\
\hline$\lambda$ & $\begin{array}{l}\text { The consumer's use experience of the product indicates the impact of contact with the product } \\
\text { on the estimated value of the product, } 0 \leq \lambda \leq 1\end{array}$ \\
\hline$S_{1}$ & $\begin{array}{l}\text { Consumers' satisfaction of purchasing products through cross-border e-commerce online chan- } \\
\text { nels }\end{array}$ \\
\hline$S_{2}$ & $\begin{array}{l}\text { Consumers' satisfaction of purchasing products through cross-border e-commerce offline chan- } \\
\text { nels }\end{array}$ \\
\hline$\eta$ & Consumer sensitivity index of cross-border logistics speed, $0<\eta<1$ \\
\hline$\beta$ & $\begin{array}{l}\text { When consumers purchase cross-border products offline, the inconvenience costs such as time } \\
\text { and travel caused by the distance are too far, } \beta>1\end{array}$ \\
\hline$a$ & Tariff cost in the process of cross-border product transportation \\
\hline$b$ & Unit penalty cost of cross-border products not arriving on schedule, $b>1$ \\
\hline k & Product storage service cost coefficient \\
\hline$\theta$ & The cost ratio of online channel to offline channel \\
\hline$z$ & Proportion of revenue shared by offline channels to online channels \\
\hline$Q_{1}$ & Consumer demand for online channels of cross-border products \\
\hline$Q_{2}$ & Consumer demand for offline channels of cross-border products \\
\hline$\pi_{S C}$ & Supply chain system profit \\
\hline$\pi_{1}$ & Online channel profit of cross-border e-commerce \\
\hline$\pi_{2}$ & Cross-border e-commerce offline channel profit \\
\hline
\end{tabular}

channel satisfaction is equal, $\alpha_{3}=\frac{P 2+\beta-P 1-\eta T}{1-\lambda}$. In order to ensure the existence of dual channels, we only consider the case of $\alpha_{1}<\alpha_{2}<\alpha_{2}$, that is, when $P 2>\frac{P 1+\eta T}{\lambda}-\beta$, because the estimated utility a of the consumer to the product obeys $(0,1)$ uniform distribution, we can get that the demand of cross-border products of online and offline channels is $Q_{1}=\int_{\alpha_{1}}^{\alpha_{3}} 1 \mathrm{~d} x=\frac{P 2+\beta-P 1-\eta T}{1-\lambda}-\frac{P 1+\eta T}{\lambda}, Q_{2}=\int_{\alpha_{3}}^{1} 1 \mathrm{~d} x=1-\frac{P 2+\beta-P 1-\eta T}{1-\lambda}$, respectively. In addition, it is assumed that the costs of customs duties and late penalties generated in the online circulation of cross-border products per unit are $c_{1}=a+(t-T) b$. In the process of offline sales, the storage cost and staff service cost are $c_{2}=\frac{k \beta^{2}}{2}$.

\subsection{Basic operation mode of cross-border e-commerce dual-channel supply chain}

\subsubsection{Centralized decision mode}

Under centralized decision-making, the online and offline channels of cross-border e-commerce cooperate. At this time, the profit function $\pi_{s c}$ of the whole supply chain system can be obtained.

$$
\pi_{s c}=\left(P 1-w-c_{1}\right) Q_{1}+\left(P 2-w-c_{2}\right) Q_{2}
$$


The first-order and second-order partial derivatives of online channel price $P 1$, offline channel price $P 2$ and planned arrival time $T$ of cross-border e-commerce are obtained from Eq. (1): $\frac{\partial^{2} \pi_{s c}}{\partial P 1^{2}}=\frac{2}{\lambda(\lambda-1)}, \frac{\partial^{2} \pi_{s c}}{\partial P 2^{2}}=\frac{2}{\lambda-1}, \quad \frac{\partial^{2} \pi_{s c}}{\partial T^{2}}=\frac{2 b \eta}{\lambda(\lambda-1)}, \quad \frac{\partial^{2} \pi_{s c}}{\partial P 2 \partial P 1}=\frac{\partial^{2} \pi_{s c}}{\partial P 1 \partial P 2}=-\frac{2}{\lambda-1}$, $\frac{\partial^{2} \pi_{s c}}{\partial P 2 \partial T}=\frac{\partial^{2} \pi_{s c}}{\partial T \partial P 2}=-\frac{b+\eta}{\lambda-1}, \frac{\partial^{2} \pi_{s c}}{\partial T \partial P 1}=\frac{\partial^{2} \pi_{s c}}{\partial P 1 \partial T}=\frac{b+\eta}{\lambda(\lambda-1)}$. Based on this, we can get that the profit of supply chain system is a strictly concave function about $P 1, P 2$ and $T$. According to the order of the function $H_{1}=\frac{2}{\lambda(\lambda-1)}<0, H_{2}=\frac{4}{\lambda(1-\lambda)}>0, H=-\frac{8 b \eta}{\lambda^{2}(\lambda-1)^{2}}<0$, Hess are negative qualitative, so there is a unique solution to the function. By solving the first-order partial derivative equations of online channel price $P 1$, offline channel price $P 2$ and planned arrival time of cross-border e-commerce $T$, we can get the following results:

$$
\begin{aligned}
& P 1=\frac{\lambda\left(2 \beta+2 w+\beta^{2} k\right)(b+\eta)-4 \eta(a+w-b t)}{4(b-\eta)}+\frac{\lambda}{2} \\
& P 2=\frac{k \beta^{2}-2 \beta+2 w+2}{4} \\
& T=\frac{2 a+2 w+2 b t-k \lambda \beta^{2}-2 \lambda \beta-2 \lambda w}{2(b-\eta)} \\
& S_{1}=\frac{\lambda\left(4 \alpha-2 \beta-2 w-k \beta^{2}-2\right)}{4} \\
& S_{2}=\frac{4 \alpha-2 \beta-2 w-k \beta^{2}-2}{4} \\
& \pi_{s c}=\frac{\left(k \beta^{2}+2 \beta+2 w-2\right)^{2}}{16}
\end{aligned}
$$

\subsubsection{Decentralized decision mode}

Under decentralized decision-making, the online and offline channels of cross-border e-commerce pursue their own profit maximization. At this time, the profit functions $\pi_{1}$ and $\pi_{2}$ of online and offline channels can be obtained, respectively.

$$
\begin{aligned}
& \pi_{1}^{N}=\left(P 1-w-c_{1}\right) Q_{1} \\
& \pi_{2}^{N}=\left(P 2-w-c_{2}\right) Q_{2}
\end{aligned}
$$

Lemma 1 Under decentralized decision-making, the online and offline product prices, demand, consumer satisfaction and total profit of cross-border e-commerce lines are, respectively, $P 1^{N}, P 2^{N}, T^{N}, S_{1}^{N}, S_{2}^{N}, \pi_{s c}^{N}$. 
Prove The online channel of cross-border e-commerce enterprises, as the leading party, first defines the price $P 1^{N}$ and the prescribed arrival time of products $T^{N}$, and then uses the reverse induction method to obtain $P 2^{N}=\frac{k \beta^{2}-2 \beta+2 P 1^{N}-2 \lambda+2 w+2 T^{N} \eta+2}{4}$. By substituting the obtained function expression about $P 2^{N}$ into Eq. (9), we can get new functional expressions about $P 1^{N}$ and $T^{N}$. We can get the first and second partial derivatives of the two variables in the formula to get the determinant of Hess matrix. Because of $\frac{\partial^{2} \pi_{1}}{\partial\left(P 1^{N}\right)^{2}}=\frac{2-\lambda}{\lambda(\lambda-1)}<0$, the online price $P 1^{N}$ and the required arrival time of the product $T^{N}$ have unique solutions. Through the calculation of simultaneous equations, we can get the online price $P 1^{N}$ and the product arrival time $T^{N}$, and then get the offline channel price $P 2^{N}$, the online and offline channel consumer satisfaction $S_{1}^{N}$ and $S_{2}^{N}$, and the online and offline channel total profit $\pi_{s c}^{N}$. The results were as follows:

$$
\begin{aligned}
& P 1^{N}=\frac{2 b \lambda(1-\lambda+w+\eta t)+b \lambda \beta(2+k \beta)}{2(b-\eta)(\lambda-2)}+\frac{\eta(a+w)}{b-\eta} \\
& P 2^{N}=\frac{2 \lambda+2 \beta-k \beta^{2}-2-2 \lambda \beta-2 w}{2(\lambda-2)} \\
& T^{N}=\frac{4 w(\lambda-1)+\lambda\left(2 \beta-2 \lambda+k \beta^{2}-2\right)}{2(b-\eta)(\lambda-2)}+\frac{a+b t}{b-\eta} \\
& S_{1}^{N}=\frac{\lambda\left(k \beta^{2}+2 \beta-4 \alpha-2 \lambda+2 w+2 \alpha \lambda+2\right)}{2(\lambda-2)} \\
& S_{2}^{N}=\frac{k \beta^{2}+2 \beta-4 \alpha-2 \lambda+2 w+2 \alpha \lambda+2}{2(\lambda-2)} \\
& \pi_{s c}^{N}=\frac{\left(k \beta^{2}+2 \beta+2 w-2\right)^{2}(1-\lambda)}{4(\lambda-2)^{2}}
\end{aligned}
$$

Lemma 2 Under decentralized decision-making, the offline channel product price, the prescribed arrival time, the online and offline channel consumer satisfaction and the supply chain system profit of cross-border e-commerce enterprises are lower than the optimal value under centralized decision-making. When $\lambda>\frac{2 \eta}{b+\eta}$, the online channel product price of cross-border e-commerce enterprises is greater than that under centralized decision-making.

Prove According to the hypothesis of the model and the symbol setting $\beta>1$ in the symbol description part, $k \beta^{2}+2 \beta+2 w-2=k \beta^{2}+2 w+2(\beta-1)>0$ can be obtained. Through calculation, we compare the online product price, offline product price, prescribed arrival time, online channel consumer satisfaction, offline channel consumer satisfaction and supply chain system profit under decentralized and centralized decision-making. The results were as follows: 


$$
\begin{aligned}
& P 1-P 1^{N}=\frac{\lambda(b \lambda-2 \eta+\lambda \eta)\left(k \beta^{2}+2 \beta+2 w-2\right)}{4(b-\eta)(\lambda-2)} \\
& P 2-P 2^{N}=\frac{\lambda\left(k \beta^{2}+2 \beta+2 w-2\right)}{4(\lambda-2)}<0 \\
& T-T^{N}=\frac{-\lambda(\lambda-1)\left(k \beta^{2}+2 \beta+2 w-2\right)}{2(\lambda-2)(b-\eta)}<0 \\
& S 1-S 1^{N}=\frac{-\lambda^{2}\left(k \beta^{2}+2 \beta+2 w-2\right)}{4(\lambda-2)}>0 \\
& S 2-S 2^{N}=\frac{-\lambda\left(k \beta^{2}+2 \beta+2 w-2\right)}{4(\lambda-2)}>0 \\
& \pi_{s c}-\pi_{s c}^{N}=\frac{\lambda^{2}\left(k \beta^{2}+2 \beta+2 w-2\right)^{2}}{16(\lambda-2)^{2}}>0
\end{aligned}
$$

From the proof of Lemma 2, it can be found that under decentralized decision-making, the offline channel product price, the prescribed arrival time, the online and offline channel consumer satisfaction and the supply chain system profit of cross-border e-commerce enterprises are lower than the optimal value under centralized decisionmaking. However, through Eq. (16), it can be found that only when $b \lambda-2 \eta+\lambda \eta>0$, that is $\lambda>\frac{2 \eta}{b+\eta}$, the online product price under decentralized decision is higher than that under centralized decision. Under the decentralized decision-making, the product price rises, but the prescribed arrival time of the product is prolonged, the consumer's satisfaction with the product decreases, and the profit of the whole supply chain system also decreases. This is because there is competition between online and offline channels under decentralized decision-making. In order to ensure product quality, infrastructure purchase and product storage increase product cost and price. When the online and offline channels cooperate, the basic cost is reduced, the logistics speed is accelerated, and the consumers can receive the products in time with lower price, and the overall profit is improved.

Lemma 3 Under decentralized and centralized decision-making, consumer satisfaction is affected by both the consumer experience and the estimated utility of the product. Under centralized decision-making, with the increase of consumers' experience of using products, the satisfaction of online and offline channels increases. With the increase of estimated utility of products, the satisfaction of consumers in online and offine channels will not be affected; in decentralized decision-making, with the increase of consumers' experience of using products, the satisfaction of both online and offline channels will increase with the increase of the estimated utility of products, the consumer satisfaction of online channel first increases and then decreases, while that of offline channel decreases. 
Prove The first-order partial derivatives of $S 1$ and $S 1^{N}$ with respect to the estimated utility of the product and the consumer's experience of the product are obtained, respectively, and $\quad \frac{\partial S 1}{\partial \alpha}=\lambda>0, \frac{\partial S 1}{\partial \lambda}=\frac{4 \alpha-2 \beta-2 w-k \beta^{2}-2}{4}>0, \quad \frac{\partial S 1^{N}}{\partial \alpha}=\lambda>0$, $\frac{\partial S 1^{N}}{\partial \lambda}=\frac{4 \alpha-2 \beta+4 \lambda-2 w-4 \alpha \lambda-k \beta^{2}+\alpha \lambda^{2}-\lambda^{2}-2}{(\lambda-2)^{2}}$ are obtained. Because we cannot distinguish the positive and negative of $\frac{\partial S 1^{N}}{\partial \lambda}$, we can get $\frac{\partial^{2} S 1^{N}}{\partial \lambda^{2}}=\frac{2\left(k \beta^{2}+2 \beta+2 w-2\right)}{(\lambda-2)^{3}}<0$ by solving the second partial derivative. Therefore, affected by the estimated utility of products, the consumer satisfaction of online channels under centralized decision-making and decentralized decision-making is on the rise; affected by the use experience of consumers on products, the consumer satisfaction of online channels under centralized decision-making is increasing, while that of online channels under decentralized decision-making first rises and then decreases. We obtain the first-order partial derivatives of $S 2$ and $S 2^{N}$ with respect to the estimated utility of the product and the consumer's experience of the product, respectively, and obtain $\frac{\partial S 2}{\partial \alpha}=\frac{\partial S 2^{N}}{\partial \alpha}=1, \frac{\partial S 2}{\partial \lambda}=0, \frac{\partial S 2^{N}}{\partial \lambda}=\frac{2-2 \beta-2 w-k \beta^{2}}{2(\lambda-2)^{2}}<0$. Therefore, affected by the estimated utility of products, the consumer satisfaction of online channels under centralized decision-making and decentralized decision-making shows an upward trend; the consumer satisfaction of online channels under centralized decision-making is not affected by consumers' use experience of products, and the consumer satisfaction of online channels under decentralized decision-making continues to decrease under the influence of consumers' use experience of products.

\section{Methods}

Relying on cloud computing, big data, artificial intelligence and other advanced technologies, it can realize the accurate and efficient matching between massive information and users, improve the service quality of cross-border e-commerce enterprises and improve the user experience. When the online and offline channels of cross-border e-commerce enterprises cooperate in the form of revenue and expense sharing contract, it is assumed that the online channel shares part of the cost for the offline channel, and the sharing proportion is $\theta$. Meanwhile, the offline channel can share part of its revenue to the online channel, and the sharing proportion is $z$. At this time, the profit functions of the online channel and the offline channel are obtained as follows:

$$
\begin{aligned}
& \pi_{1}^{Y}=\left(P 1-w-c_{1}\right) Q_{1}-\theta c_{2} Q_{2}+z P 2 Q_{2} \\
& \pi_{2}^{Y}=\left[(1-z) P 2-w-(1-\theta) c_{2}\right] Q_{2}
\end{aligned}
$$

Lemma 4 If the online and offline channels of cross-border e-commerce enterprises cooperate in the form of revenue and cost sharing contract, the decision-making combination of online and offline channels is $\left(P 1^{Y}, P 2^{Y}, T^{Y}\right)$, and the consumer satisfaction and profit of online and offline channels can be obtained as $S 1^{Y}, S 2^{Y}, \pi_{1}^{Y}, \pi_{2}^{Y}$.

Prove When online channels and offline channels cooperate by contract, online and offline channels pursue their own profit maximization. The online channel of 
cross-border e-commerce determines the price of online products and the specified arrival time of products, and the offline channel determines the price of its offline products. The first and second partial derivatives of $\pi_{1}^{Y}$ with respect to $P 1^{Y}$ and $T^{Y}$ are obtained, and the first and second partial derivatives of $\pi_{2}^{Y}$ with respect to $P 2^{Y}$ are obtained. We can get $\frac{\partial^{2} \pi_{1}^{Y}}{\partial\left(P 1^{Y}\right)^{2}}=\frac{2}{\lambda(\lambda-1)}, \quad \frac{\partial^{2} \pi_{1}^{Y}}{\partial\left(T^{Y}\right)^{2}}=0, \frac{\partial^{2} \pi_{1}^{Y}}{\partial P_{1}^{Y} \partial T^{Y}}=\frac{\partial^{2} \pi_{1}^{Y}}{\partial T^{Y} \partial P_{1}^{Y}}=\frac{\eta}{\lambda(\lambda-1)}$, $\frac{\partial^{2} \pi_{1}^{Y}}{\partial P_{1}^{Y} \partial P_{2}^{Y}}=\frac{-(z+1)}{\lambda-1}, \quad \frac{\partial^{2} \pi_{1}^{Y}}{\partial T^{Y} \partial P_{2}^{Y}}=\frac{-\eta z}{\lambda-1}, \frac{\partial^{2} \pi_{2}^{Y}}{\partial\left(P 2^{Y}\right)^{2}}=\frac{-2(z-1)}{\lambda-1}, \frac{\partial^{2} \pi_{2}^{Y}}{\partial P_{2}^{Y} \partial T^{Y}}=\frac{\eta(z-1)}{\lambda-1}, \frac{\partial^{2} \pi_{2}^{Y}}{\partial P_{2}^{Y} \partial P_{1}^{Y}}=\frac{z-1}{\lambda-1}$. Therefore, the Hess matrix of cross-border e-commerce dual channel profit function with respect to $P 1^{Y}, T^{Y}$ and $P 2^{Y}$ is $|H|=\left|\begin{array}{ccc}\frac{2}{\lambda(\lambda-1)} & \frac{-(z+1)}{\lambda-1} & \frac{\eta}{\lambda(\lambda-1)} \\ \frac{z-1}{\lambda-1} & \frac{-2(z-1)}{\lambda-1} & \frac{\eta(z-1)}{\lambda-1} \\ \frac{\eta}{\lambda(\lambda-1)} & \frac{-\eta z}{\lambda-1} & 0\end{array}\right|$. According to the order principal subformula of the function $H_{1}=\frac{2}{\lambda(\lambda-1)}<0, H_{2}=\frac{(1-z)(4-\lambda z-\lambda)}{\lambda(1-\lambda)^{2}}>0$, $H=\frac{\eta(z-1)(\lambda z+\lambda-4)}{\lambda^{2}(\lambda-1)^{3}}<0$, it can be known that the Hessian matrix is negative definite, and the unique optimal solution of the function can be obtained by solving after judgment. By solving the first-order partial derivative equations and taking the solution results into the response function of offline product price, the decision combination can be obtained as follows:

$$
\begin{aligned}
P 1^{Y}= & \frac{1}{2(b-\eta)(\lambda-2)^{2}(z-1)}\left[2 b \eta t\left(\lambda^{2}-4 z\right)+4 \lambda^{2} \eta z(\beta-1)\right. \\
& -2 b \lambda^{2} z(3-n)+4 \lambda \eta z^{2}(1-\lambda)(\beta-1) \\
& +2 \lambda \eta z(4-\lambda)(a+b t)+k \lambda \beta^{2}(\lambda-2)(b-\theta b+\theta \eta) \\
& +2 \eta t(1-\lambda)\left(4 b+\beta^{2} \theta k \lambda z\right)-2 \beta b \lambda(2+\lambda z)+2 \eta w\left(\lambda^{2}+4\right) \\
& \left.+\lambda z \eta\left(8 w+k \lambda \beta^{2}\right)+2 a \eta(\lambda-2)^{2}-2 b \lambda(\lambda-2)(\lambda-1-w)\right] \\
P 2^{Y}= & \frac{2 \lambda+2 \beta-2 w+2 z-2 \lambda \beta-2 z \beta-2 \lambda z-k \beta^{2}+2 \beta \lambda z+k \theta \beta^{2}-2}{2(\lambda-2)(1-z)} \\
T^{Y}= & \frac{1}{2(b-\eta)(\lambda-2)^{2}(z-1)}[8(w-a z-w z)(\lambda-1)+4 \lambda(\beta z-w)(\lambda-1) \\
& +2 \lambda(\lambda+1)(\lambda+2)-2 b t(\lambda+2)^{2} \\
& -\beta \lambda(\lambda-2)(2+k \beta)-2 \lambda z(\lambda-1)(2 z+\lambda-4) \\
& \left.+2 b t z(\lambda-2)^{2}-k \lambda z \beta^{2}(\lambda-2 \theta \lambda-2 \theta)-2 \lambda^{2}(\beta z+a-a z)\right] \\
S_{1}^{Y}= & \frac{2 \lambda(z-1)(\beta-\lambda+1)-2 \lambda w+k \lambda \beta^{2}(\theta-1)}{2(\lambda-2)(z-1)}+\lambda \alpha \\
S_{2}^{Y}= & \frac{2(z-1)(\beta-\lambda+1)-2 w+k \beta^{2}(\theta-1)}{2(\lambda-2)(z-1)}+\alpha \\
\pi_{1}^{Y}= & \frac{\left(k \beta^{2}(\theta-z)+2 z(\lambda-1)(1-z)(1-\beta)+k \theta \beta^{2}(z-1)(\lambda-1)-2 w z\right]}{4(\lambda-2)^{2}(z-1)^{2}} \\
& \left.+2 z \beta^{2}-2\right) \\
& \\
& \\
&
\end{aligned}
$$




$$
\pi_{2}^{Y}=\frac{\left(2+2 \beta z+k \theta \beta^{2}-2 z-2 \beta-k \beta^{2}-2 w\right)^{2}(\lambda-1)}{4(\lambda-2)^{2}(z-1)}
$$

Lemma 5 After the cooperation in the form of revenue and cost sharing contract, when the contract cooperation satisfies $z\left(1+\frac{2 w}{k \beta^{2}}\right)<\theta<\frac{\lambda(1-z)}{2}+z+\frac{\lambda(\beta+w-1)(1-z)+2 w z}{k \beta^{2}}$, there are $P_{2}^{N}>P_{2}^{Y}>P_{2}, T^{N}>T^{Y}>T, \pi_{s c}>\pi_{s c}^{Y}>\pi_{s c}^{N}, S_{1}>S_{1}^{Y}>S_{1}^{N}, S_{2}>S_{2}^{Y}>S_{2}^{N}$

Prove When the contractual cooperation satisfies $z\left(1+\frac{2 w}{k \beta^{2}}\right)<\theta<\frac{\lambda(1-z)}{2}+z+$ $\frac{\lambda(\beta+w-1)(1-z)+2 w z}{k \beta^{2}}\left\{\begin{array}{l}k \theta \beta^{2}-2 w z-k z \beta^{2}>0 \\ \lambda\left(2-2 \beta-2 w-k \beta^{2}\right)(1-z)+2\left(k \theta \beta^{2}-k z \beta^{2}-2 w z\right)<0\end{array}\right.$ can be obtained.

And

because

of $\lambda\left(2-2 \beta-2 w-k \beta^{2}\right)(1-z)+\left(k \theta \beta^{2}-k z \beta^{2}-2 w z\right)=\lambda\left(2-2 \beta-2 w-k \beta^{2}\right)(1-z)$ $+2\left(k \theta \beta^{2}-k z \beta^{2}-2 w z\right)-\left(k \theta \beta^{2}-k z \beta^{2}-2 w z\right)<0$

so

$$
P 2-P 2^{Y}=\frac{\lambda\left(2-2 \beta-2 w-k \beta^{2}\right)(1-z)+\left(k \theta \beta^{2}-k z \beta^{2}-2 w z\right)}{4(\lambda-2)(z-1)}<0
$$

$, P 2^{Y}-P 2^{N}=\frac{k \theta \beta^{2}-k z \beta^{2}-2 w z}{2(\lambda-2)(1-z)}<0, P 2^{Y}-P 2^{N}=\frac{k \theta \beta^{2}-k z \beta^{2}-2 w z}{2(\lambda-2)(1-z)}<0, P_{2}^{N}>P_{2}^{Y}>P_{2}$. At this time, by comparing the required arrival time of the product, it can be found that the product conforms to $T^{Y}-T^{N}=\frac{\lambda z(\lambda-1)\left[2 \beta(z-1)+k \beta^{2}(\theta-1)+2(1-w-z)\right]}{(\lambda-2)^{2}(z-1)(b-\eta)}<0 \quad$ and

$$
T-T^{Y}=\frac{\lambda(\lambda-1)}{2(\lambda-2)^{2}(1-z)(b-\eta)}\left[\left(2 \beta+2 \lambda+4 w+4 z-2 \lambda \beta-4 z \beta-k \lambda \beta^{2}+2 k \beta^{2}-\right.\right.
$$
4) $\left.(1-z)-2 k z \beta^{2}(1-\theta)-2 z(\beta+2 w-\lambda w)\right]<0$

According to the $\pi_{1}^{Y}$ and $\pi_{2}^{Y}$ obtained above, the system profit of the supply chain is compared,

and

$$
\pi_{s c}^{Y}=\frac{\left(2 w+2 z+2 \beta+k \beta^{2}-2 \beta z-k \theta \beta^{2}-2\right)}{4(\lambda-2)^{2}(z-1)^{2}}\left[k \theta \beta^{2}+\left(2 \beta+2 w+k \beta^{2}-2\right)(1-\lambda)(1-z)-\right.\text { is }
$$
$\left.k z \beta^{2}-2 w z\right]$

calculated. Comparing the profit of supply chain system under contract with that under centralized decision, we can get $\pi_{s c}^{Y}-\pi_{s c}^{N}=\frac{-\left(k \theta \beta^{2}-k z \beta^{2}-2 w z\right)\left[\lambda\left(2-2 \beta-2 w-k \beta^{2}\right)(1-z)+\left(k \theta \beta^{2}-k z \beta^{2}-2 w z\right)\right]}{4(\lambda-2)^{2}(z-1)^{2}}>0 \quad$ and $\pi_{s c}-\pi_{s c}^{Y}=\frac{\left[\lambda\left(2-2 \beta-2 w-k \beta^{2}\right)(1-z)+2\left(k \theta \beta^{2}-k z \beta^{2}-2 w z\right)\right]^{2}}{16(\lambda-2)^{2}(z-1)^{2}}>0$, so we can get $\pi_{s c}>\pi_{s c}^{Y}>\pi_{s c}^{N}$. Comparing the changes of customer satisfaction, we can get that $S_{1}^{Y}-S_{1}^{N}=\frac{\lambda\left(k \theta \beta^{2}-k z \beta^{2}-2 w z\right)}{2(\lambda-2)(z-1)}>0, \quad S_{2}^{Y}-S_{2}^{N}=\frac{k \theta \beta^{2}-k z \beta^{2}-2 w z}{2(\lambda-2)(z-1)}>0$. $S_{1}-S_{1}^{Y}=\frac{\lambda\left[\lambda\left(2-2 \beta-2 w-k \beta^{2}\right)(1-z)+2\left(k \theta \beta^{2}-k z \beta^{2}-2 w z\right)\right]}{4(\lambda-2)(1-z)}>0, \quad$ and $S_{2}-S_{2}^{Y}=\frac{\lambda\left(2-2 \beta-2 w-k \beta^{2}\right)(1-z)+2\left(k \theta \beta^{2}-k z \beta^{2}-2 w z\right)}{4(\lambda-2)(1-z)}>0$, so we can get $S_{1}>S_{1}^{Y}>S_{1}^{N}$, $S_{2}>S_{2}^{Y}>S_{2}^{N}$. This shows that the optimal decision of revenue sharing contract is between centralized decision and decentralized decision when the cost sharing ratio is in a certain range. Therefore, the decentralized decision-making can be optimized by adjusting the cost sharing ratio. 
Table 2 Results of parameter changes under decentralized and centralized decision

\begin{tabular}{|c|c|c|c|c|c|c|c|}
\hline $\begin{array}{l}\text { Consumers' experience of using } \\
\text { products } \lambda\end{array}$ & 0.2 & 0.3 & 0.4 & 0.5 & 0.6 & 0.7 & 0.8 \\
\hline $\begin{array}{l}\text { Product online price under centralized } \\
\text { decision }\end{array}$ & 1.4 & 929 & 4.5857 & 6.1786 & 7.7714 & 643 & 109571 \\
\hline $\begin{array}{l}\text { Product online price under decentralized } \\
\text { decision }\end{array}$ & 1.5238 & 7 & 5.6071 & 8.0 & 10.7959 & 13.9643 & 17.6429 \\
\hline Product online price under contract mode & 1.4333 & 3.3018 & 5.385 & 7.7248 & 10.3746 & 13.4036 & 16.9034 \\
\hline $\begin{array}{l}\text { Product offline price under centralized } \\
\text { decision }\end{array}$ & 4 & 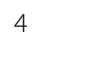 & 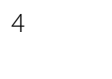 & 4 & 4 & 4 & 4 \\
\hline $\begin{array}{l}\text { Product offline price under decentralized } \\
\text { decision }\end{array}$ & 5. & 6 & 7. & 333 & 714 & 1 & 667 \\
\hline Products offline price under contract mode & 4.7302 & 5.5378 & 6.4464 & 7.4762 & 8.6531 & 10.011 & 11.5952 \\
\hline $\begin{array}{l}\text { Specified arrival time of products under } \\
\text { centralized decision }\end{array}$ & 7 & 6.0357 & 5.0714 & 4.1071 & 3.1429 & 2.1786 & 1.2143 \\
\hline $\begin{array}{l}\text { Specified arrival time of products under } \\
\text { decentralized decision }\end{array}$ & 7.8254 & 7.1828 & 6.4643 & 5.6548 & 4.7347 & 3.6786 & 2.4524 \\
\hline $\begin{array}{l}\text { Stipulated arrival time of products under } \\
\text { contract mode }\end{array}$ & 7.5639 & 6.7979 & 5.9678 & 5.0663 & 4.0862 & 3.0205 & 1.8639 \\
\hline System profit under centralized decision & 169 & 169 & 169 & 169 & 169 & 169 & 169 \\
\hline System profit under decentralized decision & 166.9136 & 163.737 & 158.438 & 150.222 & 137.959 & 120 & 93.8889 \\
\hline System profit under contract mode & 168.4669 & 166.635 & 163.015 & 156.916 & 147.349 & 132.868 & 111.312 \\
\hline
\end{tabular}

\section{Results and discussion}

In order to verify the rationality of the model and reveal the changes of cross-border e-commerce supply chain system profit and optimal decision-making under different modes, this section verifies the above conclusions. In the dual channel supply chain composed of cross-border suppliers, cross-border e-commerce enterprises and consumers, the parameter values are selected according to the parameter range in the above model, assuming that consumers' offline channel inconvenience cost $\beta=10$, consumers' sensitivity index to cross-border logistics speed $\eta=0.2$, wholesale price of products of cross-border suppliers $w=2$, tariff cost in the process of transportation $a=5$, and unit penalty for failing to arrive on schedule $b=3$, the cost coefficient of product storage service $k=0.3$, the actual arrival time of online channel products $t=6$, and the revenue ratio shared by offline channel to online channel $z=0.3$.

\subsection{The impact of consumer experience $\lambda$ on optimal decision and supply chain profit}

According to the condition $\lambda>\frac{2 \eta}{b+\eta}$ in Lemma 2, the consumer's experience $\lambda>0.125$ is obtained, and according to the condition $z\left(1+\frac{2 w}{k \beta^{2}}\right)<\theta<\frac{\lambda(1-z)}{2}+z+\frac{\lambda(\beta+w-1)(1-z)+2 w z}{k \beta^{2}}$ in lemma $5, \theta>0.34$ is obtained. In order to study the impact of consumer experience on the optimal decision-making and system profit of cross-border e-commerce products, suppose $\theta=0.4$, the following table shows the changes of online channel product price, offline channel product price, product specified arrival time and supply chain system profit under decentralized decisionmaking, centralized decision-making and revenue and cost sharing contract when $\lambda$ rises from 0.2 to 0.8 . Table 2 shows the results of parameter changes under decentralized and centralized decision. 


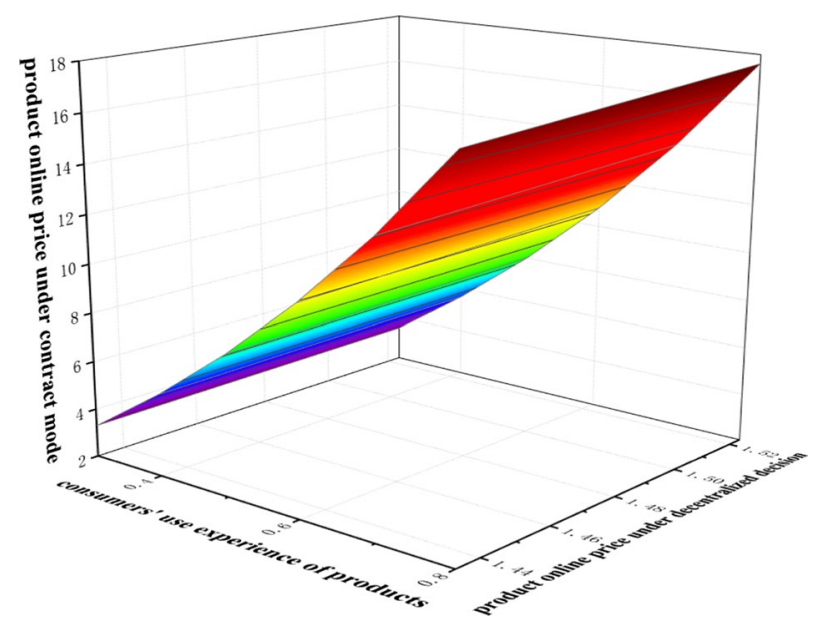

Fig. 2 Change of product online prices $P 1$ with consumer's experience in using products

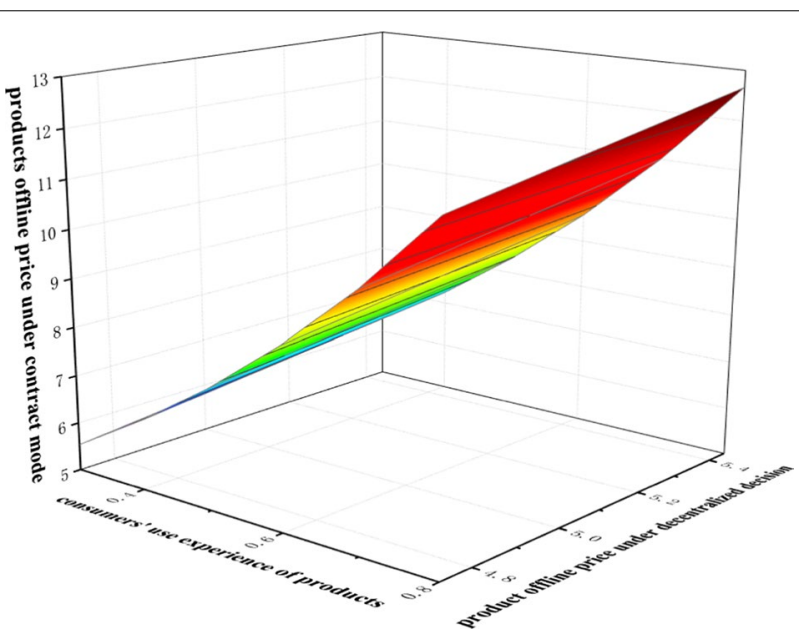

Fig. 3 Change of product offline price $P 2$ with consumer's experience in using products

It can be seen from the above table with the increase of consumers' use experience of products, the online price of products under centralized decision-making presents an upward trend, while the specified arrival time of products presents a downward trend. However, since consumers can directly contact offline products, offline prices and system profits are not affected by consumers' use experience of products. Under decentralized decision-making, the online and offline prices of products increase with the increase of consumers' use experience of products, while the prescribed arrival time of products and the profit of supply chain system decrease with the increase of consumers' use experience of products. Under the revenue and cost sharing contract, the online price, offline price, prescribed arrival time and system profit of supply chain have similar trend with decentralized decision. This is because, whether in the decentralized decision-making mode or the contract mode, the higher the consumer's experience of using the product, the smaller the impact of consumer's contact with the product on the estimated value 


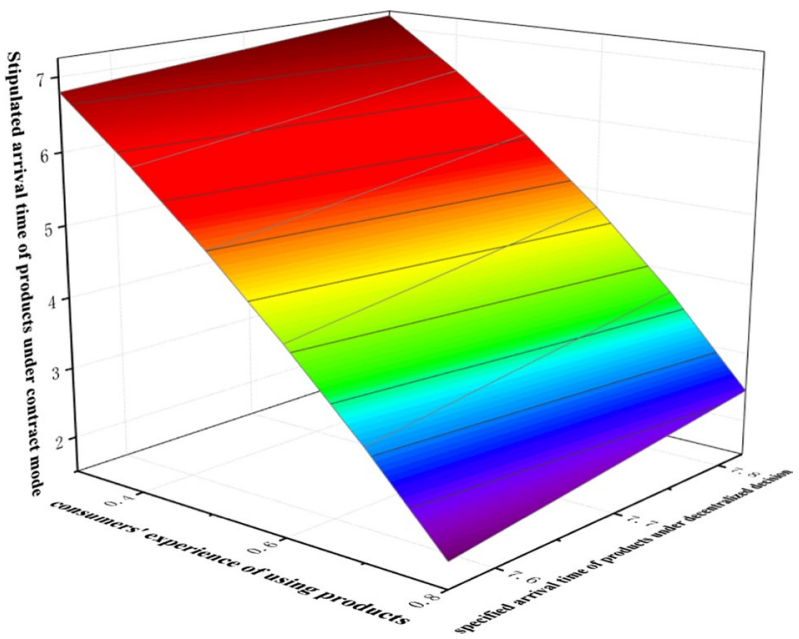

Fig. 4 Change of product arrival time $T$ with consumer's experience in using products

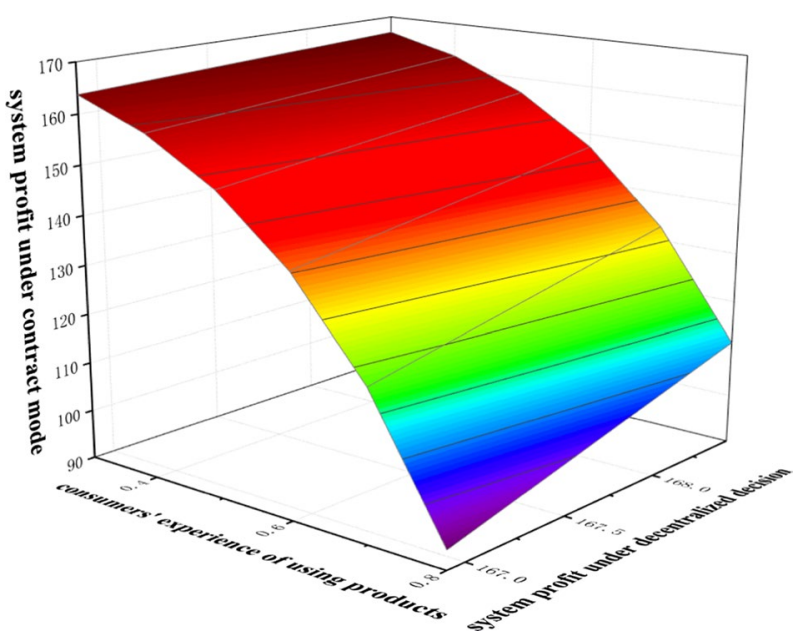

Fig. 5 Change of system profit $\pi_{s c}$ with consumer's experience in using products

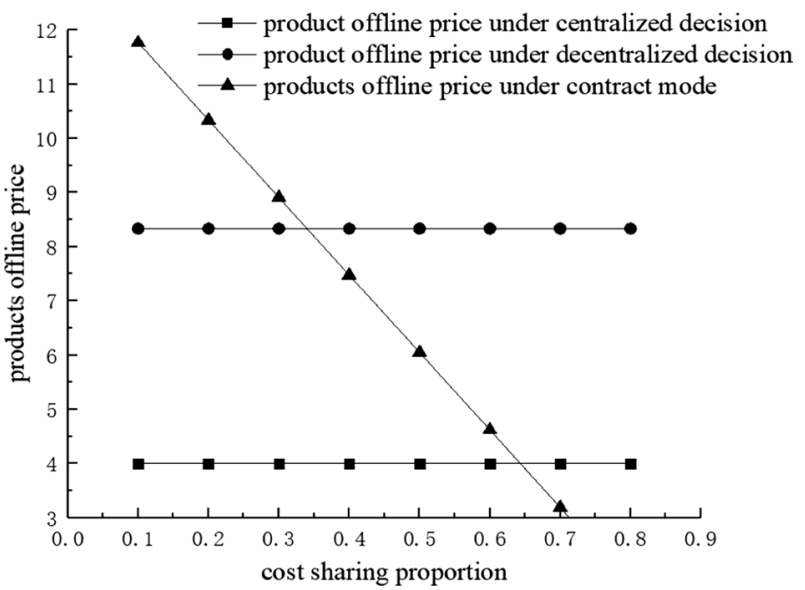

Fig. 6 Change of product offline price $P 2$ with cost share proportion 


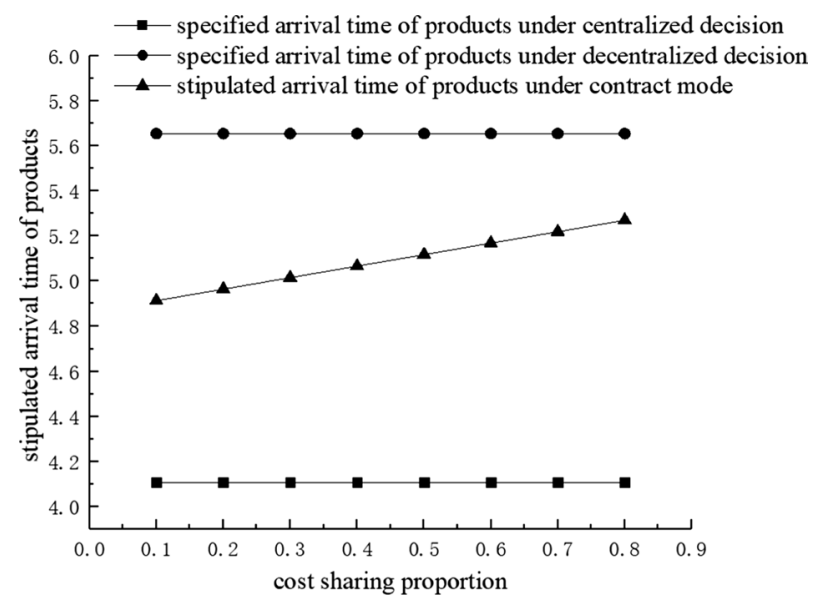

Fig. 7 Change of product arrival time $T$ with cost share proportion

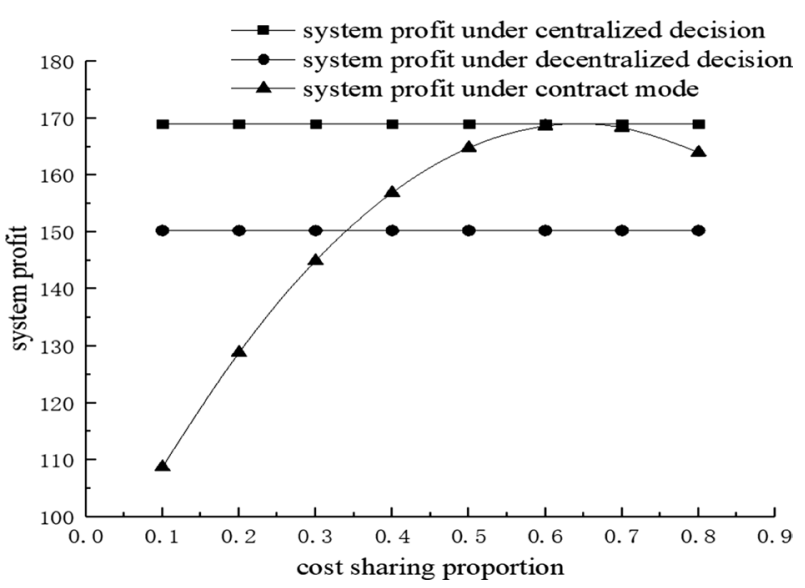

Fig. 8 Change of system profit $\pi_{s c}$ with cost share proportion

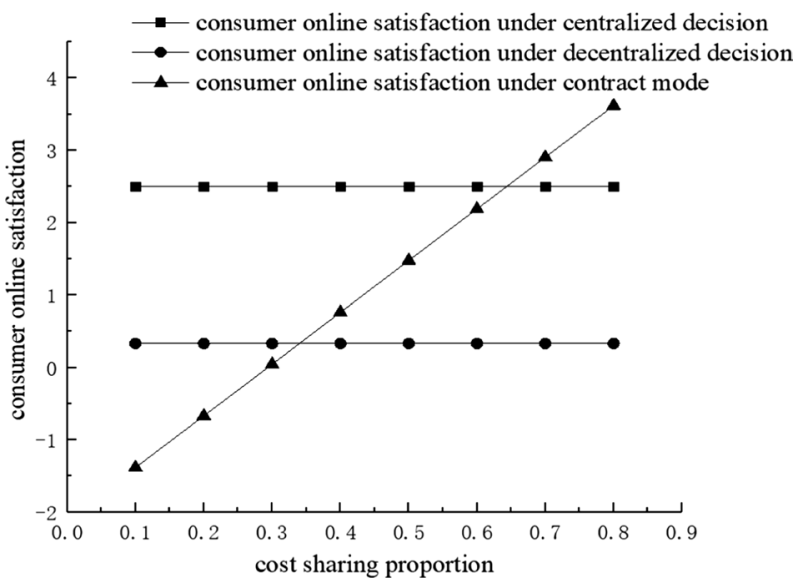

Fig. 9 Change of consumer online satisfaction $S_{1}$ with cost share proportion 


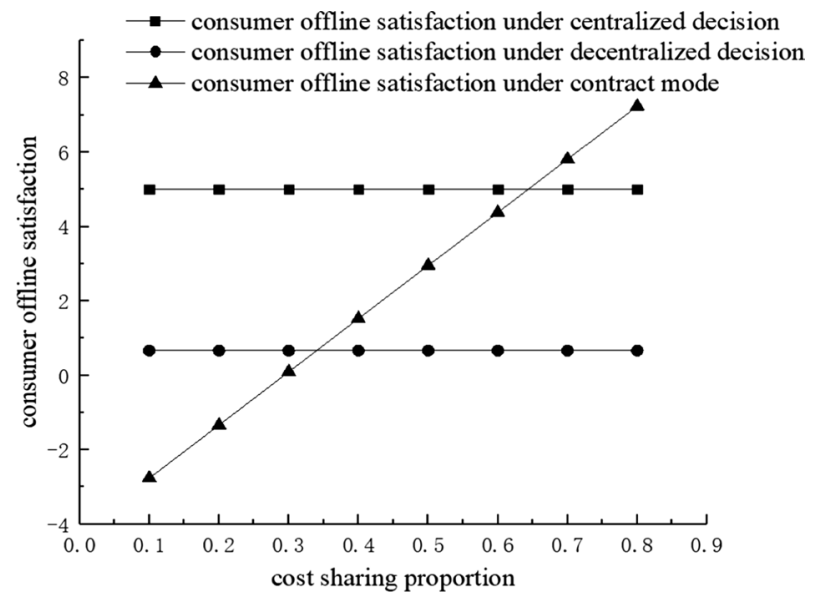

Fig. 10 Change of consumer offline satisfaction $S_{2}$ with cost share proportion

of the product, and the closer the evaluation value of the product to the fixed value, the more stable the consumer's demand will be. When cross-border e-commerce enterprises set the prices of online and offline channel products and the prescribed delivery time of products, they should provide different prices and product delivery time according to the consumers' experience of using the products. That is to say, when consumers have high acceptance of products, they can be equipped with higher online and offline prices and shorter product receiving time to attract consumers and gain profits. In order to observe the trend of decentralized decision-making and revenue and cost sharing contract mode more intuitively and clearly, and to select the more advantageous model among them, Figs. 2, 3, 4 and 5 are shown as follows.

It can be seen from Figs. 2, 3, 4 and 5 that with the increase of consumers' experience of using products, the rising trend of product prices in online and offline channels of crossborder e-commerce under contract mode is significantly lower than that of decentralized decision-making, while the downward trend of prescribed arrival time of products under contract mode is stronger than that of decentralized decision-making. Generally speaking, the model under contract mode has more advantages than the model under decentralized decision-making. Enterprises can obtain higher profits of supply chain system, and consumers can buy products with higher consumer experience with more affordable product price and faster expected arrival time. Cross-border e-commerce enterprises can choose to reoptimize decentralized decision-making by forming contracts through online and offline channels, so as to achieve effective coordination.

\subsection{The influence of cost sharing ratio $\theta$ on optimal decision}

In the case of decentralized decision-making, centralized decision-making and revenue and expense sharing contract, if the cost sharing ratio between the two channels changes, then the optimal decision-making in the three situations will change, and the optimization mode of enterprise selection will also change accordingly. In order to make a more intuitive and simple comparison, suppose $\alpha=19, \lambda=0.5$, and get the offline channel product price, product specified arrival time, supply chain system profit, online 
channel consumer satisfaction and offline channel consumer satisfaction in three cases, as shown in Figs. 6, 7, 8, 9 and 10.

It can be seen from these five pictures that the price of offline products under the contract agreement decreases with the increase of cost sharing proportion, the specified arrival time of products and the satisfaction of online and offline consumers present an upward trend, while the profit of supply chain system increases first and then decreases with the increase of cost sharing proportion. This is because the offline channel as the leader, when the higher proportion of cost sharing, reduce the cost pressure of offline channel, the lower the product price of offline channel. With the increase of cost sharing ratio, cross-border e-commerce enterprises can provide better products for consumers, and consumer satisfaction of both channels will increase. At the same time, it is found that when the cost sharing ratio is in the range of [0.34, 0.643], the offline channel product price, the product specified arrival time, the online and offline channel consumer satisfaction and the supply chain system profit value are between decentralized decision and centralized decision. At this time, we can optimize the decision-making and improve customer satisfaction by adjusting the cost sharing ratio, and at the same time improve the profit of the supply chain. Therefore, the choice of revenue and cost sharing contract model can regulate the supply chain and achieve win-win cooperation.

\section{Conclusion}

Based on the consideration of consumer satisfaction, this paper constructs a dual channel supply chain composed of cross-border suppliers, cross-border e-commerce enterprises and consumers and studies the decision-making optimization problems of the supply chain under the conditions of centralized decision-making, decentralized decision-making and revenue and cost sharing contract. The research shows that the profit of cross-border e-commerce supply chain system and the satisfaction of online and offline customers are low under decentralized decision-making, which cannot meet the profit demand of enterprises and satisfy consumers. The model under contract mode has more advantages than the model under decentralized decision-making. Enterprises can obtain higher profits of supply chain system, and consumers can buy products with higher consumer experience with more affordable product price and faster expected arrival time. Cooperation through revenue and cost sharing contract can play a very good regulatory role, which can improve consumer satisfaction and ensure the interests of the main supply chain, so as to achieve win-win cooperation. In order to improve the satisfaction of consumers, this paper chooses the optimal supply chain coordination method for research and finally finds that the revenue cost sharing contract can be used to coordinate the supply chain, which is meaningful to promote the decision-making optimization of the supply chain and improve the satisfaction of consumers. However, the consumer demand in this paper is continuous and stable, and the research on the supply chain of cross-border e-commerce enterprises under demand interruption needs to be discussed in the future. 
Funding

This work was supported by National Social Science Foundation of China [Grant Number: 18CGL015].

Availability of data and materials

Data sharing is not applicable to this article as no datasets were generated or analyzed during the current study.

\section{Competing interests}

The authors declare that they have no competing interests.

Received: 24 November 2020 Accepted: 26 January 2021

Published online: 06 February 2021

\section{References}

1. J.H. Li, Personalized recommendation algorithm based on big data for artificial intelligence cross border E-commerce shopping platform. Sci. Technol. Eng. 19(14), 280-285 (2019)

2. X. Wu, Y.Y. Wei, Y.Q. Mao et al., A differential privacy DNA motif finding method based on closed frequent patterns. Clust. Comput. 22(3), 1-13 (2018)

3. H.B. Liang, J.L. Zou, K. Zuo et al., An improved genetic algorithm optimization fuzzy controller applied to the wellhead back pressure control system. Mech. Syst. Signal Proc. 142(8), 106708 (2020)

4. Z.J. Chen, Y.S. Zhang, C.Z. Wu et al., Understanding individualization driving states via latent Dirichlet allocation model. IEEE Intell. Transp. Syst. Mag. 11(2), 41-53 (2019)

5. H.F. Zheng, W.Z. Guo, N.X. Xiong, A kernel-based compressive sensing approach for mobile data gathering in wireless sensor network systems. IEEE Trans. Syst. Man Cybern. Syst. 48(12), 2315-2327 (2017)

6. D.R. Liu, D.F. Li, X.X. Deng, Product pricing considering channel service level in cross-border E-commerce environment. Comput. Integr. Manuf. Syst. 26(08), 2278-2287 (2020)

7. Y.N. Zhao, Influencing factors of cross-border E-Commerce trade between China and "Belt and Road" coastal and inland countries. J. Coast. Res. 103(sp1), 70-73 (2020)

8. X.Wu, H.H. Wang, D.S. Wei et al., ANFIS with natural language processing and gray relational analysis based cloud computing framework for real time energy efficient resource allocation. Comput. Commun. 150(1), 122-130 (2020)

9. Z. Liu, B. Hu, B.T. Huang et al., Decision optimization of low-carbon dual-channel supply chain of auto parts based on smart city architecture. Complexity. 05, 1-14 (2020)

10. H.B. Liang, D.L. Zou, Z.L. Li et al., Dynamic evaluation of drilling leakage risk based on fuzzy theory and PSO-SVR algorithm. Futur. Gener. Comp. Syst. 95(6), 454-466 (2019)

11. Z.J. Chen, H. Cai, Y.S. Zhang et al., A novel sparse representation model for pedestrian abnormal trajectory understanding. Expert Syst. Appl. 138(12), 112753 (2019)

12. H.Y. Yang, F.F. Zhou, Y.J. Tian, Study on consumers' food safety satisfaction based on association rule. Manag. Rev. 32(4), 286-297 (2020)

13. Z. Liu, Y.J. Zhao, B. Hu et al., Research on staged pricing model and simulation of intelligent urban transportation. IEEE Access 7(9), 141404-141413 (2019)

14. F.C. Ma, C.Y. Li, Research on E-commerce consumer satisfaction measurement of fresh products-analysis based on online reviews of JD Fresh. Price Theory Pract 14(05), 117-120 (2020)

15. N. Xiong, W. Han, A. Vandenberg, Green cloud computing schemes based on networks: a survey. IET Commun. 6(18), 3294-3300 (2012)

16. S. Sunhee, K. Kawon, N. VietaAnnisa, Satisfaction and purchase intention of imported fresh fruits based on familiarity: a case of Korean pears in Taiwan. Br. Food J. 122(9), 2895-2910 (2020)

17. M.Y. Zhang, D. Zhang, H.J. Yao et al., A probabilistic model of human error assessment for autonomous cargo ships focusing on human-autonomy collaboration. Saf. Sci. 130(10), 104838 (2020)

18. W.Z. Guo, N.X. Xiong, H.C. Chao et al., Design and analysis of self-adapted task scheduling strategies in wireless sensor networks. Sensors. 11(7), 6533-6554 (2011)

19. S.J. Sang, Q. Zhang, Coordination mechanisms analysis of green supply chain with reference price effect. J. Syst. Manag. 30(5), 994-1002 (2020)

20. F. Xu, H.L. Wang, Ordering and coordination in a dual-channel supply chain under the difference of due date. Oper. Res. Manag. Sci. 12(4), 121-129 (2020)

21. L.L. Shu, S.J. Qu, Z. Wu, Supply chain coordination with optimal pricing and logistics service decision in online retailing. Arab. J. Sci. Eng. 45(3), 2247-2261 (2020)

22. Y.B. Li, C.X. Wang, Two stage supply chain optimization and coordination based on rate of profit to cost. J. Ind. Eng. 32(1), 100-106 (2018)

23. X.L. Ma, S.Y. Wang, H. Jin et al., Coordination and optimization of three-echelon agricultural product supply chain considering freshness-keeping effort and quantity/quality elasticity. Chin. J. Manag. Sci. 40(2), 175-185 (2018)

24. Z. Liu, B. Hu, Y.J. Zhao et al., Research on intelligent decision of low carbon supply chain based on carbon tax constraints in Human-driven edge computing. IEEE Access 8(3), 48264-48273 (2020)

25. H. Golpîra, H. Sadeghi, S. Bahramara, Electricity supply chain coordination: Newsvendor model for optimal contract design. J. Clean Prod. 278(1), 1-21 (2020)

26. L.W. Jiang, S.F. Ji, Q. Sun et al., Research on channel selection and pricing strategies by considering brand APP pichness in $\mathrm{O} 2 \mathrm{O}$ supply chain. J. Ind. Eng. 30(03), 178-187 (2018)

27. J.S. Hu, Y.J. Ji, D.Q. Ma, Research on quality and service strategy of ECSC enterprises based on consumer utility. Syst. Eng. Theory Pract. 41(10), 2602-2616 (2020)

28. X. Fu, G. Fortino, W. Li, P. Pace, Y. Yang, WSNs-assisted opportunistic network for low-latency message forwarding in sparse settings. Future Gen. Comput. Syst. 91(2), 223-237 (2019) 
29. X. Fu, Y. Yang, Modeling and analysis of cascading node-link failures in multi-sink wireless sensor networks. Reliab. Eng. Syst. Saf. 197(5), 106815 (2020)

30. X. Fu, P. Pace, G. Aloi, L. Yang, G. Fortino, Topology optimization against cascading failures on wireless sensor networks using a memetic algorithm. Comput. Netw. 177(8), 107327 (2020)

31. Q. Long, C. Wu, X. Wang, A system of nonsmooth equations solver based upon subgradient method. Appl. Math. Comput. 251(1), 284-299 (2015)

32. J. Zhu, Q. Shi, P. Wu, Z. Sheng, X. Wang, Complexity analysis of prefabrication contractors' dynamic price competition in mega projects with different competition strategies. Complexity 9, 1-9 (2018)

33. K. Shi, J. Wang, S. Zhong, Y. Tang, J. Cheng, Non-fragile memory filtering of T-S fuzzy delayed neural networks based on switched fuzzy sampled-data control. Fuzzy Sets Syst. 394(9), 40-64 (2019)

34. K. Shi, Y. Tang, S. Zhong, C. Yin, X. Huang, W. Wang, Nonfragile asynchronous control for uncertain chaotic Lurie network systems with Bernoulli stochastic process. Int. J. Robust Nonlinear Control 28(5), 1693-1714 (2018)

35. K. Shi, Y. Tang, X. Liu, S. Zhong, Non-fragile sampled-data robust synchronization of uncertain delayed chaotic Lurie systems with randomly occurring controller gain fluctuation. ISA Trans. 66(1), 185-199 (2017)

36. K. Shi, Y. Tang, X. Liu, S. Zhong, Secondary delay-partition approach on robust performance analysis for uncertain time-varying Lurie nonlinear control system. Optim. Control Appl. Methods 38(6), 1208-1226 (2017)

37. M. Xu, T. Li, Z. Wang, X. Deng, R. Yang, Z. Guan, Reducing complexity of HEVC: a deep learning approach. IEEE Trans. Image Process. 27(10), 5044-5059 (2018)

38. C. Liu, X. Deng, J. Liu, T. Peng, S. Yang, Z. Zheng, Dynamic response of saddle membrane structure under hail impact. Eng. Struct. 214(7), 110597 (2020)

39. J. Liu, C. Wu, G. Wu, X. Wang, A novel differential search algorithm and applications for structure design. Appl. Math. Comput. 268(10), 246-269 (2015)

40. Z. LV, W. Xiu, Interaction of edge-cloud computing based on SDN and NFV for next generation loT. IEEE Internet Things J. 7(7), 5706-5712 (2020)

41. Z. Lv, H. Song, Mobile internet of things under data physical fusion technology. IEEE Internet Things J. 7(5), 4616-4624 (2020)

42. J. Ren, C. Zhang, Q. Hao, A theoretical method to evaluate honeynet potency. Future Gen. Comput. Syst. 116(3), 76-85 (2020)

43. B. Cao, W. Dong, Z. Lv, Y. Gu, S. Singh, P. Kumar, Hybrid microgrid many-objective sizing optimization with fuzzy decision. IEEE Trans. Fuzzy Syst. 28(11), 2702-2710 (2020)

44. B. Cao, X. Wang, W. Zhang, H. Song, Z. Lv, A many-objective optimization model of industrial internet of things based on private blockchain. IEEE Netw. 34(5), 78-83 (2020)

45. J. Yan, W. Pu, S. Zhou, H. Liu, M.S. Greco, Optimal resource allocation for asynchronous multiple targets tracking in heterogeneous radar networks. IEEE Trans. Signal Process. 68(7), 4055-4068 (2020)

46. H. Zhang, Z. Qiu, J. Cao, M. Abdel-Aty, L. Xiong, Event-triggered synchronization for neutral-type semi-Markovian neural networks with partial mode-dependent time-varying delays. IEEE Trans. Neural Netw. Learn. Syst. 31(11), $1-14(2019)$

47. J. Zhao, J. Liu, J. Jiang, F. Gao, Efficient deployment with geometric analysis for mmWave UAV communications. IEEE Wirel. Commun. Lett. 9(7), 1115-1119 (2020)

48. J. Chen, G. Liu, Y. Liu, Lightweight privacy-preserving raw data publishing scheme. IEEE Trans. Emerg. Top. Comput. 1 , 4 (2020). https://doi.org/10.1109/TETC.2020.2974183

49. B. Wang, B.F. Zhang, X.W. Liu, An image encryption approach on the basis of a time delay chaotic system. Optik 225(1), $165737(2021)$

50. B. Wang, B.F. Zhang, X.W. Liu, F.C. Zou, Novel infrared image enhancement optimization algorithm combined with DFOCS. Optik 224(12), 165476 (2020)

\section{Publisher's Note}

Springer Nature remains neutral with regard to jurisdictional claims in published maps and institutional affiliations.

\section{Submit your manuscript to a SpringerOpen ${ }^{\circ}$ journal and benefit from:}

- Convenient online submission

- Rigorous peer review

- Open access: articles freely available online

- High visibility within the field

- Retaining the copyright to your article

Submit your next manuscript at $\gg$ springeropen.com 